\title{
Nombres (im)propios de la A a la Z. Breves apuntes sobre nombres, identidades, cuerpos y agencia narrativa
}

\author{
Yera Moreno SAInz-EzQuerRa \\ Universidad Complutense de Madrid \\ yeramoreno@hotmail.com
}

Recibido: 16-05-2014

Aceptado: 13-04-2015

\section{Resumen}

El presente artículo forma parte de un proceso abierto de investigación en el que se abordan las relaciones, fricciones, posibilidades y transformaciones entre nombres, cuerpos e identidades. A partir de la concepción de los nombres propios como actos performativos que, más allá de describir la identidad de quien porta dicho nombre, la producen, se propone el análisis del nombre propio como soporte narrativo fundamental para la ficción de una identidad homogénea, estable, fija y unitaria. Desde una perspectiva de pensamiento crítica y antiesencialista respecto a la categoría de identidad, el nombre propio será examinado como un elemento clave en la construcción de las identidades individuales y su ficción en tanto que estables y unitarias a lo largo del tiempo. Los cambios de nombre suponen, así, una brecha y una posibilidad de ruptura, a la vez que ofrecen la oportunidad de (re)narrarnos, mostrando la inestabilidad, rearticulación y heterogeneidad de las identidades.

Palabras clave: Nombres propios, identidades, actos performativos, agencia. 


\title{
(Im)Proper Names from $A$ to $Z$. \\ Brief Notes on Names, Identities, Bodies and Narrative Agency
}

\begin{abstract}
This article is part of a research process that explores the relations, frictions, possibilities and transformations between names, bodies and identities. Based on the conception of proper names, understood as performative acts that not only describe the identity of the name bearer but create that very identity, this paper aims to analyse the proper name as a basic narrative structure sustaining over time the fiction of a homogeneous, stable and unified identity. From the perspective of critical thinking and anti-essentialism applied to the identity category, the proper name will be considered as a key element in the construction of individual identities and the embodiment of a fictional essence. Name changes thus point to a gap and a potential rupture, offering the opportunity to show us in a different light, while revealing the instability, re-articulation and heterogeneity of identities.
\end{abstract}

Keywords: Proper Names; Identities; Performative Acts; Agency.

\section{Referencia normalizada}

Moreno SAInZ-EzQuerra, Yera (2015): "Nombres (im)propios de la A a la Z. Breves apuntes sobre nombres, identidades, cuerpos y agencia narrativa”, Política y Sociedad, 52 (2), pp. 539-556.

Sumario: 1. Introducción. 2. Nombres propios. La nominación o lo que los nombres "son". 3. El nombrar y el reconocimiento. 4. "Los circuitos del yo". Nombres, géneros, sexos, cuerpos e identidad(es). 5. Cortocircuitando el yo. Re-nombres y agencia narrativa. 6. Bibliografía. 
¿Cuál es la relación entre nombres y descripciones?

Saul Kripke, El nombrar y la necesidad.

Alrededor del nombre de uno se amontonan las cosas -dijo Berenice-. Tú tienes un nombre y te van ocurriendo cosas una después de otra, y tú te portas de variadas maneras y haces eso y aquello, de modo que el nombre empieza pronto a tener una significación. Las cosas se han ido juntando alrededor del nombre.

Carson McCullers, Frankie y la boda.

El nombre propio nunca ha sido, como apelación única reservada a la presencia de un ser único, más que el mito de origen de una legibilidad transparente y presente bajo la obliteración.

Jacques Derrida, De la Gramatología.

\section{Introducción}

Partiendo de una perspectiva antiesencialista y crítica con categorías como la de identidad, que serán repensadas y comprendidas en términos de procesos performativos (Butler, 1990/2007) y articulaciones inestables abiertas a un exterior constitutivo (Laclau y Mouffe, 1985/2006), a lo largo de este artículo analizaremos la función de los nombres "propios" en la construcción de la identidad ${ }^{1} \mathrm{y}$ de su posterior "esencialización", por la que se ocultan los mecanismos de articulación y rearticulación de las identidades, que acaban siendo mostradas en términos de esencias inmutables, fijas, homogéneas y unitarias. El objetivo de este análisis, para el que nos serviremos tanto de las tesis antidescriptivistas, como de las teorías de la performatividad ${ }^{2}$, de la crítica antiesencialista y de la teoría queer, será mostrar que el nombre propio es el soporte fundamental para la producción de las identidades individuales y de su ficción en tanto que estables y fijas a lo largo del tiempo. En este sentido, y retomando las tesis antidescriptivistas de S. Kripke, diremos que el nombre fija una referencia (Kripke, 1981/1995: 105) y,

${ }^{1}$ La noción de identidad a la que nos referiremos a lo largo de este artículo remite a una perspectiva entendida en términos individualistas y modernos, es decir, al modelo hegemónico identitario presente en la cultura occidental desde la Modernidad. Debemos tener en cuenta, no obstante, que ésta es una noción particular de la identidad que no opera por igual en todas las culturas, y que en otras sociedades el proceso de articulación identitario no se estructura en los mismos términos individualistas ni bajo el tipo de nominación que es analizado en estas páginas.

${ }^{2}$ Incluiríamos, dentro de las teorías de la performatividad, el trabajo desarrollado por J. L. Austin sobre los enunciados performativos, las posteriores tesis de J. Derrida, y la lectura de J. Butler a partir de los dos pensadores y su desplazamiento y reformulación en torno al género, la sexualidad y el sujeto. 
desplazando esta tesis al campo de las identidades, añadiremos que además de fijar la referencia la produce, es decir, que cada vez que nos nombran y nos nombramos producimos la identidad que el nombre está fijando y, a su vez, produciendo. Este artículo pretende, por ello, visibilizar esta función productiva de los nombres propios en relación a la identidad, mostrándose que es el nombre el que produce la identidad que supuestamente "describe", por lo que no habría identidad (ni sujeto) anterior a este proceso de nominación.

Entenderemos, así mismo, que la propia referencia al nombre como "propio" contribuye a la producción del mito de la identidad en estos términos al indicar, por un lado, que a cada identidad, comprendida como individual, única y autónoma, le corresponde un nombre propio que describiría esa unicidad, singularidad y excepcionalidad de su portador. Por otro, la referencia al nombre "propio" señala que este nombre nos pertenece, que es de nuestra propiedad, aun cuando nos haya venido impuesto por otras personas (a menudo el núcleo familiar en el que nacemos), haya sido institucionalizado a través de diferentes registros normativos sociales que van desde el bautismo, en sociedades católicas, a los registros civiles, y que a partir de dichos mecanismos normativizadores nos identifique. Todo ello produce e impone una supuesta correspondencia entre el nombre, la identidad y el cuerpo al que refiere ese nombre, que se muestra como condición imprescindible para ser nombrado y reconocido socialmente, pues para poder existir necesitamos (y se nos exige) ser nombrados, y serlo bajo un nombre que sea el mismo a lo largo de toda nuestra vida. Además, tal y como veremos en las páginas que siguen, este proceso de nominación/producción identitaria está atravesado por múltiples normativas y convenciones sociales, entre las que tendrán una importancia fundamental las normativas de género/sexo en la medida en que toda identidad será siempre, por exigencias sociales, una identidad generizada.

El nombre propio se convierte, de este modo, en uno de los pilares normalizadores y normativizadores en lo que denominaremos el "circuito del yo" (Butler, 1993/2008: 220). No es de extrañar que el nombre propio acabe siendo así una de las características que definan a lo considerado "humano", que se articula como "dotado de narratividad, memoria, deseos, interioridad psíquica" (Romero Bachiller, 2008: 144) y, en definitiva, de una historia personal e "individual" que, precisamente, va estructurándose en torno al nombre propio. Si tenemos en cuenta que el proceso de articulación de lo humano

${ }^{3}$ Como ejemplo cotidiano de esta función que ejerce el nombre propio en todo proceso de humanización podemos señalar el acto de poner un nombre propio a aquellos animales que pasan a formar parte de los contextos domésticos y que son socializados dentro de estos contextos. La referencia a ellos a través de la nominación personal puede ser leída, desde esta perspectiva, como una fase imprescindible en su proceso de "humanización" y domesticación. En el lado contrario, la negativa a nominar individualmente a los animales en aquellos contextos en los que estos están destinados a formar parte de las cadenas alimentarias de consumo (granjas, mataderos), indicaría, también, la importancia de la nominación personal en la humanización. 
se produce dentro de contextos normativos, y sobre la base de toda una serie de exclusiones que sitúan en los márgenes a aquellos cuerpos considerados "abyectos" (Butler, 1993/2008), podemos subrayar como una de las exigencias en el reconocimiento de los cuerpos humanos será que sean identificados con un nombre que les es "propio" y que, supuestamente, designa su singularidad como cuerpos humanos. El nombre propio será, por consiguiente, un mecanismo fundamental en la normativización (y normalización) de los cuerpos y su "necesaria" correlación con una identidad generizada y sexualizada.

Tal y como veremos al final de este artículo, la elección de otros nombres para nombrarnos y renarrarnos, especialmente cuanto estos cambios transgreden el binarismo de género/sexo en el que las identidades son formuladas, mostrará las brechas y fisuras en todo el proceso de articulación de la identidad, lo aleatorio de los mecanismos que definen dichas identidades, así como las posibilidades que estas fisuras permiten y que los cambios de nombre provocan. Todo ello nos permitirá hablar de cortocircuitos del yo, de disrrupciones y agencias narrativas gracias a las cuales el yo, y la identidad ligada a él, que se articula por la referencia al nombre propio, es puesto en entredicho, cuestionado, fracturado y visibilizado como un proceso articulatorio frágil, abierto e inestable, en el que constantemente nos estamos produciendo y postproduciendo conforme a unos marcos normativos que nos dan reconocimiento y existencia social al nombrarnos singularmente como humanos.

\section{Nombres propios \\ La nominación o lo que los nombres "son"}

Las tesis antidescriptivistas, unidas a la teoría de la performatividad, permitirán analizar la función del nombre propio como productor de la identidad y no bajo una función meramente descriptiva. Para los antidescriptivistas, cuyo máximo representante será la figura de $\mathrm{S}$. Kripke, los nombres propios son "designadores rígidos" (Kripke, 1981/1995: 51) que fijan la referencia al nombrar. Así, cada vez que nos referimos a alguien por su nombre, estamos fijando la referencia de dicho nombre, que designará al mismo objeto (en este caso a la misma persona) cada vez que es nombrada. Frente a las posturas descriptivistas que consideran que el nombre describe su referente bajo una serie de rasgos descriptivos que hacen que reconozcamos ese objeto cada vez que es nombrado, la perspectiva antidescriptivista hablará del llamado "bautismo primigenio" para poner en cuestión esa mera función "descriptiva" de los nombres. Los nombres, mediante ese bautismo primitivo en que a un objeto se le asigna un nombre (en el campo que nos ocupa nos referiremos a ese acto simbólico, e institucionalizado, que consiste en poner un nombre a la persona recién nacida), continúan refiriéndose a su objeto de referencia "aun cuando todos los rasgos descriptivos del objeto en el momento de su bautismo hayan desaparecido" (Žižek, 1989/1992: 16). Si el nombre designa 
rígidamente el mismo objeto aun cuando los rasgos descriptivos a los que refería el nombre hayan desaparecido, fijando por tanto su referencia "en todo mundo posible" (Kripke, 1981/1995: 51) ¿cuál es la relación entre los nombres y los objetos a los que se refieren dichos nombres?

Si desplazamos esta cuestión al campo de las identidades y los cuerpos cabe preguntarse cuál es la relación entre los nombres propios, con los que somos designados al nacer, nuestra identidad y nuestros cuerpos a los que esos nombres refieren, a pesar de que el cuerpo esté en un proceso continuo de cambio (visible y reconocible socialmente) y que tampoco eso que habitualmente denominamos "identidad" sea la misma a lo largo del tiempo. Parece claro que el nombre propio fija su referencia, o lo que es lo mismo, que designa el "mismo" referente aun cuando los "rasgos" hayan cambiado. Esta fijación de la referencia es lo que establece al nombre propio como uno de los criterios identificatorios para las administraciones estatales, pues el nombre nos identifica como "los mismos" aunque nuestros rasgos físicos y características corporales hayan cambiado perceptiblemente ${ }^{4}$. Todo ello nos permite (re)pensar esta vinculación entre nombres propios e identidades y preguntarnos si el nombre está describiendo una referencia (una identidad singular e individual y que es asumida bajo aquello que llamaremos “cuerpo) o, más bien, está produciéndola cada vez que la nombra.

Analizar el estatus del nombre propio bajo esta perspectiva nos permitirá, no sólo subrayar el papel clave que juega el nombre en el proceso de articulación de las identidades y en su estabilidad y fijación, sino desvelar la fragilidad de dicho proceso, su inestabilidad, así como los mecanismos sociales, repetitivos y ritualizados, que constantemente son puestos en marcha para sedimentar y esencializar unos identidades que, lejos de ser tales esencias fijas y homogéneas, necesitan de dichos mecanismos para ser estabilizadas. Así, las tesis antidescriptivistas de Kripke nos permiten, de entrada, afirmar que "el nombre propio asegura la identidad del objeto a lo largo del tiempo" (Butler, 1993/2008: 221) y que lo hace, precisamente, fijando una referencia cuya única estabilidad y homogeneidad es el nombre propio que la está produciendo cada vez que es nombrada en esos mismos términos "esencializadores". En este sentido el nombre propio, al fijar un proceso inestable de articulación y rearticulación constante, necesariamente abierto, constituido social y normativamente, que denominamos identidad individual y que se estructura en torno al nombre que le da su fijeza e inmovilidad, lo transforma en sustancia, en esencia, e "incluso, parece recordar a una sustancia metafísica de ese tipo de seres diferenciados y singulares" (Butler, 1997/2004: 63).

${ }^{4}$ Son, sin embargo, estos mismos soportes identificatorios los que visibilizan la relación precaria e inestable entre nombres, cuerpos e identidades, como demuestra la necesidad de renovación del documento nacional de identidad, en el contexto español por ejemplo, cada ciertos años. Esta renovación implica reconocer "la transformación y el cambio, por lo que se fuerza su renovación cada cierto tiempo para que los reconocimientos sean posibles" (Romero Bachiller, 2008: 148). 
Si el nombre fija su referencia cada vez que la nombra, convirtiendo así a esa referencia en una especie de esencia "inmutable" que es reconocida como igual a sí misma a lo largo de la vida, se debe a lo que Žižek denominará el "efecto retroactivo de la nominación" (Žižek, 1989/1992: 134). Para Žižek las tesis antidescriptivistas de Kripke pasan por alto este efecto retroactivo del nombre, pero es precisamente este punto el que más nos interesa para repensar la vinculación entre nombres propios e identidades desde una teoría performativa, pues el efecto retroactivo del nombre señala, precisamente, que es el nombre, el significante, el soporte de la identidad del objeto (Žižek, 1989/1992: 135). No se trata, por tanto, de que el nombre describa su referencia, sino que la constituye retroactivamente. En último término, lo que garantiza así la identidad de un objeto es su nombre, gracias a este efecto retroactivo. El nombre, por consiguiente, unifica, estructura y fija en torno a sí un campo determinado de flujos y procesos inestables, cambiantes, precarios y en constante rearticulación, constituyendo la identidad de aquello que está nombrando. Podemos afirmar, por ello, que el nombre propio tiene un poder constitutivo y no meramente descriptivo.

Este efecto retroactivo del nombrar abre nuevos caminos para pensar las relaciones entre referentes y referencias en la nominación, entre nombres propios, sujetos e identidades, y nos permite afirmar que no hay sujeto constituido previo a ese acto de nombrar, sino que más bien es el nombre el que nos está produciendo como sujetos. Podemos así pues desplazar las afirmaciones de Derrida respecto a la firma al campo de los nombres propios y las identidades, y si "la firma inventa al signatario" (Derrida, 1984/ 2009: 17), que no existe antes del acto de la firma, el nombre propio inventa (produce) al sujeto; lo inventa cada vez que lo nombra y lo dota de una ficticia estabilidad y unidad a lo largo del tiempo. El nombre propio se convierte, de este modo, en una especie de "móvil inmutable"5 (Latour y Hermant, 1999: 175) pues dota a la identidad de una aparente inmutabilidad y estatismo, cuando es justamente el nombre quien la está produciendo en esos términos estáticos y ocultando los mecanismos de su constitución. El poder constitutivo del nombre queda de esta manera oculto tras una aparente función descriptiva, lo que provoca un efecto de identidad previamente constituida y anterior al propio acto de nombrar.

Si el nombre propio produce la identidad que supuestamente describe, si es el que "da el sentido, en lugar de reflejarlo" (Halberstam, 2008: 49), podemos afirmar que el nombre es un performativo (Austin, 1971/1998), en el sentido en que al nombrar crea la realidad que supuestamente refleja. Como performativo al decir algo está haciéndolo, pues al nombrarnos nos está produciendo como sujetos, como reconocibles e "idénticos a nosotros mismos", y necesita por ello de la repetición y la ritualización, de

${ }^{5}$ El móvil inmutable, según es concebido por Latour y Hermant, permite a su vez "la movilidad de las relaciones y la inmutabilidad de lo que transporta". Si desplazamos este concepto al campo de la nominación, el nombre permite la movilidad de la identidad, que evidentemente no es la misma a lo largo de toda su existencia bajo un mismo nombre, al tiempo que la estabiliza y la fija como inmutable bajo ese nombre. 
ser continuamente nombrados bajo el mismo nombre, de que éste permanezca siendo el mismo a lo largo de nuestra vida, que sea reconocido por otros, que aparezca como criterio identificador de "lo que somos" en diferentes documentos administrativos; que asegure, de este modo, nuestra identidad y permita nuestra identificación.

El nombre propio puede ser así leído como "un sitio de identificación" (Butler, 1993/2008: 207) que debe ser repetido, reiterado y reconocido socialmente, normativamente, y que cada vez que es repetido nos está produciendo como sujetos individuales, únicos, no iguales a otros, estables, homogéneos, cerrados, y lo hace performativamente. Cada vez que nos nombran y nos nombramos estamos produciendo nuestra identidad, nos estamos produciendo como sujetos ${ }^{6}$. De este modo el nombrarnos y designarnos bajo un mismo nombre hace posible nuestro reconocimiento y, a su vez, nos está asignando una estabilidad, una historia y una memoria que es constantemente estructurada y postproducida ${ }^{7}$ alrededor de ese nombre que nos es "propio", narrándonos y produciéndonos desde el presente del nombre, desde un "ahora en general, en la forma trascendental del mantenimiento" (Derrida, 1989: 370). Todo el proceso heterogéneo, inestable, continuo, contradictorio, frágil y múltiple que supone la articulación de la identidad es estructurado alrededor de un nombre propio que tiende a estabilizarnos y producirnos como "iguales a nosotros mismos" a lo largo de toda nuestra vida. Tal vez cabría preguntarse, por ello, ¿qué queda de la identidad sin el nombre propio que la está constituyendo?

${ }^{6}$ Al referirnos a la producción del sujeto no nos referimos a la idea de un sujeto dentro de un marco humanista que considera al sujeto previamente constituido, voluntarista y que se construye a sí mismo como proyecto. Por el contrario hacemos referencia a la concepción de un sujeto postsoberano, que se constituye en el hacer, performativamente, a través de un proceso continuo de actos que tienen como efecto la producción del sujeto. Si según las tesis de J. Butler (Butler, 1990 / 2007) no hay sujeto previo a sus actos, sino como efecto de estos, en el mismo sentido, y llevado a la cuestión de la nominación, la tesis central de este artículo es que previamente al nombre propio no habría identidad (ni sujeto), pues para constituirnos como tal necesitamos del proceso de nominación.

${ }^{7}$ Por memoria postproducida entenderemos la función básica de la memoria que, lejos de ser un fiel registro de hechos pasados acontecidos, es un continuo ejercicio de postproducción de los recuerdos, que son relatados y reconstruidos siempre desde el presente, lo que supone un trabajo de edición y ficcionalización. La memoria, en este sentido, es siempre postproducida: narrada y contada desde un presente que convierte y construye ciertos hechos pasados en recuerdos y lanza a sus márgenes (al olvido) aquello que no se quiere recordar. Se trata, por tanto, de un relato en el que nos contamos a nosotras/os mismos.

Dentro de este ejercicio de postproducción que supone la memoria el nombre es un soporte básico, al ser el centro en torno al cual estructuramos esos recuerdos que nos vamos narrando bajo la historia de ese (nuestro) nombre. Sobre la memoria como postproducción consultar: Villaplana, Virginia, "Mediabiografía. Tecnologías de la memoria”. 


\section{El nombrar y el reconocimiento}

El nombre propio, en tanto que acto performativo, surge en un contexto normativo, convencional y ritualizado, en el que el nombre es reconocido (e impuesto) por otros como rasgo identitario y singular de un sujeto. De esta forma el nombre propio es parte esencial en la formación del sujeto, siendo "uno de los rituales más influyentes en la formación y reformulación de los sujetos" (Butler, 1997/2004: 256). El nombre propio ha de ser por ello legible, es decir "repetible, iterable, imitable" (Derrida, 1989: 371); surgido en un contexto primigenio de nominación pero cuya iterabilidad, citacionalidad y constante repetición implica la ruptura con ese contexto originario en el que ha surgido y permite, a su vez, que sigamos siendo reconocidos bajo un mismo nombre que cada vez que se repite, que es citado, está produciendo al sujeto y dándole existencia social. Esta repetición ritualizada del nombre, ejemplificada a diario en un constante ejercicio de nominación continuo (a través de múltiples documentos en los que firmamos con nuestros nombres, en los que somos llamados por ellos, en los que somos reconocidos a través de dichos nombres), nos da existencia social como sujetos, sujetándonos a una categoría discursiva que como tal nos "somete" a una estabilidad y a la norma pero que a su vez nos permite, desde el nombre, tener capacidad de actuar, de ser sujetos políticos con agencia, aun cuando esta se dé, precisamente, dentro de contextos fuertemente normativos donde la capacidad de acción es, si bien limitada, no determinada a priori (Butler, 1997/2004: 228); por ello las posibilidades de subvertir la norma desde la citacionalidad no pueden ser establecidas a priori, ahí reside, precisamente, su potencial para la transformación social ${ }^{8}$.

El nombre propio, como performativo, ha de ser creible, y para lograr su legitimidad deber ser producido conforme a unas normas ${ }^{9}$, dentro de un contexto normativo que le otorga su credibilidad y legitimidad a través de la citacionalidad. Sin embargo cada vez que el nombre (y por consiguiente el sujeto) es citado, y por tanto repetido y puesto "en escena" socialmente, se produce cierta distancia respecto a la norma, cierta ruptura con el contexto normativo en el que ha surgido, y es en esta brecha donde, como

${ }^{8}$ Aclararemos, no obstante, y tal y como subraya Beatriz Preciado que "no hay, ni puede haber, una relación causal necesaria entre citación performativa y subversión" (Preciado, 2011: 98). En este sentido no todos los actos performativos son necesariamente subversivos; lo que señala la distancia o "brecha" de la citacionalidad es la posibilidad de subvertir el contexto de citación en el que el acto performativo se produce. Llevado al campo de la nominación, si bien el nombre nos produce como sujetos dentro de contextos normativos, es desde ese mismo soporte nominal y normativo en el que existimos como sujetos desde donde podemos reapropiarnos de la norma y subvertirla.

${ }^{9}$ En el caso del nombre propio la credibilidad de este viene otorgada por el cumplimiento de una serie de normas reguladas por la legislación estatal que imponen, por ejemplo, una obligatoria correspondencia entre nombres y cuerpos según un binarismo sexo/genérico, como veremos en las páginas que siguen al abordar la legislación española respecto al registro de nombres. 
veremos, se sitúa la agencia para subvertir la norma, para renarrarnos y renombrarnos, desvelando los mecanismos normativos y precarios por los que se constituye el sujeto. La asignación del nombre propio (y su reconocimiento) es, por tanto, un acto social que requiere de un "contexto intersubjetivo" (Butler, 1997/2004: 56) en el que son las otras personas quienes nos dan un nombre, quienes nos lo imponen, y son las instituciones sociales quienes reconocen legalmente ese nombre y, a partir de dicho "bautismo", nos identifican con él como sujetos sociales. El nombrar forma así parte de un pacto social "mediante el cual dos sujetos llegan a acordar simultáneamente el reconocimiento del mismo objeto" (Butler, 1993/2008: 220). Y en este pacto, en el que, a través de la nominación la referencia queda fijada socialmente, el proceso inestable de articulación de la identidad queda estabilizado y fijado, queda esencializado a costa de que ese nombre (y su portador) sean reconocidos socialmente.

Judith Butler, en su revisión crítica de la categoría de sujeto e identidad, retomará la "interpelación" en Althusser para desvelar esa posición en la producción del sujeto según la cual es al ser interpelados (nombrados) por otros como el sujeto es reconocido como tal, siendo este reconocimiento constitutivo del sujeto. Nos constituimos, de este modo, como sujetos en un acto social de interpelación en que el somos nombrados/ llamados por otros. Esta interpelación supone que el sujeto se constituye en la sujeción a la norma, en contextos siempre normativos que nos sujetan a ciertas categorías discursivas que nos dan existencia como sujetos sociales, y es sin embargo desde esta sujeción desde la cual el sujeto puede exceder la norma, transformarla y subvertirla, tal y como J. Butler ha subrayado insistentemente en su trabajo. Si el proceso de subjetivación es siempre un proceso social de normativización, ello no conlleva que el sujeto no tenga cierta capacidad de acción dentro de esta producción normativa; la ambivalen$\mathrm{cia}^{10}$ del sujeto se muestra precisamente en que sólo tenemos capacidad de acción una vez que somos reconocidos (y por tanto nombrados y constituidos) normativamente como sujetos. Pues bien, en este proceso productivo en el que somos interpelados, y cuya interpelación permite nuestro reconocimiento social, la nominación personal ejerce un papel fundamental. Somos interpelados por otros bajo un nombre que ha de ser singular, propio, único pero a su vez reproductible y citable en el tiempo, reconocible, y es este acto de nominación el que nos otorga existencia social, aunque esta existencia social sea posible porque hemos sido estabilizados y normalizados bajo un nombre propio que nos está constituyendo como sujetos. La nominación personal implica así un reconocimiento constituyente del sujeto, que es siempre un proceso normativo y discursivo; de este modo "ser llamado por un nombre es también una de las condiciones por las que un sujeto se constituye en el lenguaje" (Butler, 1997/2004: 17).

${ }^{10}$ La ambivalencia del sujeto refiere a esa característica en la producción del sujeto según la cual éste se constituye en la norma, sujeto a contextos normativos, pero donde estas normas no actúan de forma determinista. Es precisamente en la reiterabilidad de la norma donde se sitúa la capacidad de acción para volver la norma en su propia contra. Sobre la "ambivalencia" del sujeto recomendamos BUTLER, Judith (1997a). 
Si tal y como Foucault mostrará en sus investigaciones en torno a la cuestión del sujeto, el sujeto se constituye "a través de técnicas de poder que individualizan a los seres humanos y perfilan sus identidad" (Vázquez García, 1997: 149), el nombre propio ejerce un papel esencial en esta individuación de los sujetos y en su constitución. Así, en el sentido en que a partir fundamentalmente de Foucault ${ }^{11}$ el sujeto pierde su estatus de "fundamento" de lo social y pasa a ser cuestionado y repensado de forma crítica como proceso histórico, social (y normativamente) constituido en el discurso, es decir, dentro de estructuras discursivas que "exceden y preceden al sujeto" y que son siempre normativas, la asignación del nombre propio es requisito indispensable para su constitución. Identidad, subjetividad y nominación quedan así entrelazadas dentro de contextos normativos en los que para poder existir necesitamos ser nombrados, y serlo bajo unos parámetros normativos concentrados en torno al nombre propio ${ }^{12}$.

La nominación, por consiguiente, nos permite ocupar un lugar desde el que ser y estar, aún cuando este lugar haya sido constituido por y a través de técnicas de poder y de normas. No obstante es desde aquí, desde el nombre propio, desde el cual podemos también ejercer poder, excediendo las normas, renarrándonos y visibilizando las fracturas inherentes a todo proceso de producción de sujetos e identidades. Así pues, "el nombre por el que se le llama a uno te subordina y te capacita, produciendo una situación de agencia desde la ambivalencia, un conjunto de efectos que exceden las intenciones de la nominación" (Butler, 1997/2004: 261, énfasis añadido). En este sentido, y como subraya Beatriz Preciado en referencia al trabajo de J. Butler, lo que interesa no es tanto "cómo la ley determina posiciones de sujeto, sino si es posible y cómo desobedecer esta ley interpelante, introducir fallos en el proceso normativo de subjetivación" (Preciado, 2011: 88). Revelar así al nombre propio como productor de la identidad y del sujeto, dentro de una producción que es siempre normativa, supone, además de un ejercicio de análisis crítico, un ejercicio político para posibles reapropiaciones, para abrir fisuras en los procesos normativos, para (re) narrarnos, desde el nombre, como sujetos (im)propios.

${ }^{11}$ Si bien el cuestionamiento crítico de la categoría de sujeto según es concebido en el proyecto de la Modernidad está ya presente en la llamada filosofía de la "sospecha", en la que destaca la figura de Nietzsche.

${ }^{12}$ Como ejemplo de la importancia del nombre propio para la existencia social recomendamos el trabajo de la artista Manal Al Dowayan "My name is". En él la artista pide a diferentes mujeres saudíes que escriban su nombre en objetos cerámicos que son expuestos públicamente. Con este acto de visibilizar los nombres de las mujeres en el espacio de lo público la artista reflexiona en torno a una práctica bastante aceptada en la sociedad saudí según la cual a los hombres les resulta ofensivo mencionar los nombres de las mujeres en sus vidas y las propias mujeres ocultan su nombre/identidad para no ofender a los miembros de sus familias y entorno cercano. Esta in-existencia de los nombres femeninos en el habla pública supone un ejercicio intencionado de invisibilización de las mujeres, en tanto que borrar el nombre implica borrar a la persona que lo lleva. Para más información sobre el proyecto consultar: <manaldowayan.com/> 


\section{4. "Los circuitos del yo" Nombres, géneros, sexos, cuerpos e identidad(es)}

Tomaremos el término de Lacan "el circuito del yo" para designar ese perímetro social y normativo que se articula conformando lo que denominamos "yo" entre nombres, cuerpos e identidades y en el que el nombre, como hemos venido señalando, se sitúa como "punto nodal" que articula y constituye el propio circuito. El nombre propio es así asignado a un cuerpo, y produce una identidad "corporal", estructurando el itinerario del yo que queda estabilizado, fijado y articulado en función de una serie de coherencias impuestas socialmente. En este sentido a cada nombre propio ha de corresponderle un cuerpo, que "designará" una identidad, generizada y sexualizada, que debe ser coherente con respecto al nombre propio asignado. El circuito del yo queda de este modo cerrado ${ }^{13}$ normativamente y según unos parámetros pactados socialmente y cuyos garantes son las instituciones estatales y administrativas y la legislación, que produce con sus normas, al yo en esos términos de coherencia entre nombre-cuerpo-identidad. El yo sedimenta, a través de su ficción narrativa como nombre propio, todo este proceso constante de articulación y rearticulación que supone la identidad, quedando ocultos los mecanismos normativos y las exclusiones que dicho proceso supone, y naturalizando una coherencia y estabilidad que sólo se consiguen por el propio proceso performativo de repetir un nombre que, con cada repetición, produce la ficción de un yo coherente y de un cuerpo en correspondencia con el nombre que le ha sido impuesto. Queda así cerrado un círculo entre el nombre, el cuerpo y la identidad que debe mantenerse cerrado para poder funcionar como sujetos, pero cuya sutura es un ejercicio constante de normalización a través de diferentes trámites cotidianos que desde las estructuras estatales se nos exigen para que el yo, en esos términos, siga funcionando como elemento identificatorio de los sujetos individuales y singulares reconocibles bajo el nombre propio.

Los documentos identificatorios que se nos exigen ser mostrados para casi cualquier tipo de trámite (desde los más cotidianos a los más burocráticos) funcionan, por ello, como importantes elementos "para establecer la identidad" (Platero, 2011: 600), y hacerlo en función de unos parámetros normativos que exigen la "coherencia" entre cuerpo, género y sexo a través del nombre. No es de extrañar, en este sentido, que uno de los elementos que contiene cualquier documento oficial, cuyo objetivo último es la identificación de los sujetos, y, yendo más allá, la propia producción del sujeto y de la identidad, sea el nombre propio y los apellidos. Y que este nombre, en el caso del contexto español, imponga un género, dentro de un sistema binario, que debe coincidir con la marca de sexo (Platero, 2011: 600). El nombre propio nos está así produciendo como

${ }^{13}$ En tanto que el yo, como ficción narrativa de un proceso articulatorio múltiple, performativo y precario, escapa a cualquier tipo de cierre o sutura completa, siempre hay espacio para la fuga, como los cambios de nombre visibilizan. 
sujetos generizados, con una identidad generizada que se produce (y legítima) cada vez que somos nombrados en los diferentes papeles que a diario debemos rellenar y mostrar. Todo este contexto burocrático y administrativo en el que estamos inmersos para poder sobrevivir socialmente (desde acudir a la escuela a ir al médico) puede ser así considerado el contexto normativo en el que el nombre propio produce sujetos, identidades y cuerpos generizados. La identidad necesita por ello de toda esta cadena de documentos oficiales para ser fijada, establecida y estabilizada a través del nombrar, que es el primer elemento que se nos requiere cada vez que se pide nuestra identificación.

Dean Spade (Spade, 2008: 740) señalará como la formación del Estado Moderno requerirá la capacidad de localizar a los ciudadanos de modo inequívoco, y para que dicha localización sea posible necesitará de toda una serie de documentos administrativos cuya función será establecer la identidad (y la identificación). Así, el Estado Moderno hará deseable distinguir individualmente ${ }^{14}$ a los sujetos (Spade, 2008: 741), y el nombre y los apellidos serán elementos imprescindibles en esta individualización. Si a ello le añadimos que en una gran parte de los contextos administrativos de los estados modernos hay una clara imposición de género en la nominación, como es el caso de la legislación española, y que consiguientemente esta nominación está estableciendo nuestra identidad generizadamente, parece evidente que el circuito del yo se estructura normativamente a través de unos sistemas clasificatorios en los que el nombre ocupa un importante lugar articulatorio, y donde dichos sistemas producen las realidades (y las identidades) que supuestamente están clasificando. Si, por tanto, nuestra tesis inicial de trabajo era que el nombre propio produce la identidad (y la produce desde una perspectiva "esencializadora"), a ello añadiremos que la está produciendo generizadamente, delimitando un perímetro donde el yo es construido y ficcionalizado como cuerpo generizado, en correspondencia con una marca de sexo impuesta al nacer y bajo el paraguas del nombre propio.

La legislación española respecto a la asignación y registro de nombres nos ofrece un buen ejemplo de este contexto normativo que nos produce, e identifica, como sujetos generizados. Parece llamativo que, si bien desde las agencias estatales se promulga la libertad de elección en el nombre, y se aclara que "casi todos los nombres son hoy posibles"15, la ley a su vez establezca ciertas prohibiciones en esta libre elección entre

${ }^{14}$ Un ejemplo de esta necesidad de distinguir individualmente a los sujetos sería la prohibición, en la legislación española, de atribuir a un hermano el nombre de otro hermano vivo, pues ello supondría una duplicidad "identitaria" que haría imposible la identificación individual y singular que el estado impone y que nos produce como sujetos individuales, únicos y distintos a otros. Resulta llamativo, por el contrario, que una costumbre bastante arraigada dentro de los núcleos familiares haya sido asignar a un hermano el nombre de otro anteriormente fallecido, lo que suele considerarse como un "homenaje" en el que la persona fallecida pervive de cierta forma en la memoria familiar a través del nombre asignado al hermano vivo.

15 Fuente consultada: Ministerio de Justicia:

<http://www.mjusticia.gob.es/cs/Satellite/es/1200666550200/Tramite_C/1214483962185/Detalle.html> 
las que se incluye que no se admiten los nombres que hagan confusa la identificación (por ejemplo un apellido convertido en nombre) ni los que introduzcan en su conjunto a error sobre el sexo. Así, la Ley de Registro Civil de 8 de Junio de 1957 en su artículo 54 prohíbe expresamente los nombres que induzcan en su conjunto a error sobre el sexo, y el Reglamento del Registro Civil de 14 de Noviembre de 1958 en su artículo 192 de nuevo expresa la prohibición de cualquier nombre que haga confusa la designación o induzca a error respecto al sexo. Esta legislación implica, por tanto, la obligatoriedad de portar nombres que no sean "ambiguos" respecto al sexo, o lo que es lo mismo, que estén claramente marcados de forma generizada. Otro ejemplo de esta necesaria correspondencia que la ley impone entre nombres y cuerpos generizados la encontramos en la Ley 3/2007, de 15 de Marzo, reguladora de la rectificación registral de la mención relativa al sexo de las personas. Según la citada ley, en su artículo 1, "la rectificación del sexo conllevará el cambio del nombre propio de la persona, a efectos de que no resulte discordante con su sexo registral". La ley, por tanto, obliga al cambio de nombre una vez que se haya rectificado la marca de sexo del registro para que haya "concordancia" entre el nombre y el sexo. Vemos, en definitiva, como las diversas leyes que regulan los registros de nombre permiten los cambios de nombre, pero siempre que los nuevos nombres no sean genéricamente ambiguos.

Lo relevante aquí, desde una lectura crítica donde estamos abordando la labor productiva de la nominación, es ir más allá de los mecanismos impositivos y represivos de la legislación para resaltar que el lenguaje legislativo oculta sus mecanismos productivos. Al hablar de "error sobre el sexo" y "hacer confusa la identificación" está "naturalizando" un proceso y un circuito normativo (el de identidades-cuerpos-nombres) que la propia ley está produciendo en esos términos generizados y sexualizados. La ley, de este modo, aparenta simplemente reflejar una clasificación de los cuerpos, en términos de sexo-género, en función de la cual el nombre propio ha de estar en "concordancia", cuando es sin embargo la propia ley la que está produciendo dicha clasificación normativa, y lo hace precisamente a través de la imposición de unos nombres que han de ser marcados genéricamente. No se trata únicamente de que la ley imponga un nombre genéricamente marcado y que este deba ser concordante con la marca de sexo asignada al portador de dicho nombre, sino que además, con este gesto "impositivo", la ley está produciéndonos como sujetos generizados, como cuerpos sexualizados dentro de un sistema de clasificación binario. En este sentido la legislación refleja, retomando una de las tesis más influyentes de Foucault (Foucault, 1978/1995), que el poder no es sólo represivo, sino también productivo, y es esta función productiva del poder (por la que nos constituimos como sujetos) la que más atención requiere en nuestros análisis críticos, pues en estos circuitos productivos de poder en los que nos constituimos normativamente, está también la posibilidad para volver el poder en su contra y crear disrrupciones que conlleven cortocircuitos del sistema. 


\section{Cortocircuitando el yo Re-nombres y agencia narrativa}

Judith Halberstam retoma el concepto de Eve K. Sedwick de "taxonomías inmediatas" (Sedwick, 1990/1998: 38) en referencia a aquellas "categorías que usamos a diario para interpretar nuestro mundo y que funcionan tan bien que en realidad no las reconocemos" (Halberstam, 2008: 31). En este sentido el nombre propio, tal y como ha venido siendo analizado a lo largo de este artículo, podría ser considerado una "taxonomía inmediata", pues nos permite interpretar el mundo (a las otras personas, y a nosotras mismas) en función de unas identidades constituidas social y normativamente y que funcionan dentro del contexto social gracias a un pacto intersubjetivo. La importancia de desvelar el nombre propio como taxonomía inmediata reside, precisamente, en que deja de ser visto como algo neutro y meramente descriptivo para ser visibilizado como una categoría productiva, y, por tanto, como un término pactado, impuesto y reconocido normativamente que apoya, legitima y produce cierta forma hegemónica de clasificar el mundo y lo humano. El nombre propio abandona así su estatus descriptivo y se muestra como una de las categorías clave en la producción de sujetos, identidades y cuerpos generizados, y en la legitimación de unas identidades que han de ser homogéneas, cerradas, estables y únicas para ser coherentes y funcionar socialmente según los marcos normativos que las están constituyendo a través de la nominación. No obstante este proceso se articula con brechas y fisuras, puntos de fuga que permiten, de una parte, mostrar los mecanismos normativos que constituyen el propio proceso y, por otra, aprovechar la fuga para renarrarnos y rearticularnos, para poner en entredicho esa idea de yo estable que se impone socialmente para el reconocimiento y la identificación. Los cambios de nombre suponen, en este sentido, una ruptura dentro del supuesto circuito "cerrado" del yo, y desvelan al propio yo como ficción, como relato narrado en torno a un nombre propio. Así mismo, el cambio de nombre nos permite darle la vuelta a esa imposición de la nominación, pues es a partir del nombre desde el que somos llamados, desde donde "decidimos" nominarnos de otra(s) forma(s).

Para Judith Butler (Butler 2004/2006) la agencia (agency) remite a la capacidad de acción de un sujeto constituido en la norma, es decir, dentro de marcos normativos de los que no podemos escapar pero donde sí tenemos cierta capacidad de acción. Esta capacidad de acción alude precisamente a esa condición ambivalente del sujeto en tanto que sujeto a la norma pero con capacidad de acción para subvertir la norma que lo ha constituido. El sujeto dotado de agencia es dependiente del contexto (normativo, social, discursivo) en el que se ha constituido, de ahí que su capacidad de acción sea siempre "interna y no externa al poder" (Burgos, 2008: 240), y es que esta agencia surge precisamente en el proceso performativo que produce al sujeto, en la citacionalidad de la norma, o dicho de otra forma, en el fracaso del performativo. Es en la ruptura del performativo con su contexto, en esa brecha (o distancia) que se produce cada vez que 
performamos la norma, cuando surge la capacidad de acción del sujeto. Ésta, por tanto, no ha de ser entendida como la capacidad de acción de un sujeto voluntarista previamente constituido, no se trata de "una propiedad del sujeto sino de un efecto del poder" (Butler 1997/2004: 228). El sujeto, en este sentido, actúa dentro del campo normativo en el que se constituye y donde las "restricciones son al mismo tiempo posibilidades" (Butler 1997/2004: 73, N. de los T.).

Teniendo en cuenta esta conceptualización del término agencia, y en la medida en que el sujeto, para constituirse como tal, necesita de la nominación personal, de un nombre propio que se le impone pero que, a su vez, le otorga reconocimiento social (le constituye como sujeto) y, por tanto, le permite actuar, los cambios de nombre pueden ser considerados un ejemplo de lo que denominaremos agencia narrativa. En el sentido en que consideramos al yo como una ficción de todo un proceso articulatorio, frágil, inestable y múltiple que se estructura (y delimita) en torno al nombre propio, el yo supone un ejercicio constante de narratividad, de contarnos a nosotras y nosotros mismos en función de una historia coherente en la que la memoria, articulada sobre el nombre propio, ejerce un papel fundamental. En la medida en que el yo es nuestra propia narración, y el nombre es tanto nuestro soporte narrativo como el soporte que permite la narración que los otros hacen de aquello que consideran "nuestro yo", los cambios de nombre, los re-nombres, pueden ser así leídos como prácticas de agencia narrativa, como ejercicio de nuestra (limitada) capacidad de acción para contarnos de nuevo, para renarrarnos, para crear nuevos personajes que pasan por una nueva nominación elegida desde el nombre que nos fue impuesto. Así, esta elección se produce siempre dentro del marco normativo, de la estructura discursiva en la que nos constituimos como sujetos, pero donde los re-nombres, o los nuevos nombres para narrarnos, crean esas disrrupciones en el proceso de estabilización de las identidades que el nombre propio provoca. Además, visibilizan lo precario de todo el proceso, su apertura constante al exterior constitutivo, así como la necesidad del reconocimiento social para ser nombrados (y reconocidos) por nuestros nuevos nombres.

Se muestran, gracias a ello, los mecanismos de poder que atraviesan todo el proceso de articulación de las identidades y, sobre todo, que aquellos sujetos "nominados" singularmente, en base a un nombre que les es propio y que les distingue, individualiza y singulariza, sólo pueden constituirse como tales en tanto que sujetos sociales, en dependencia de los otros y de su reconocimiento. Por ello el cambio de nombre, a la vez que supone una agencia narrativa evidencia que esta nunca es propiedad exclusiva del sujeto, sino que se produce en contextos sociales donde nuestra agencia está limitada por el reconocimiento de los otros. Prueba de ello son todos los mecanismos, tanto institucionales como cotidianos, que se activan al cambiar de nombre. Necesitamos ser nombrados por los otros con nuestro nuevo nombre para que éste sea reconocido (y reconocible). Y a menudo estos procesos de nueva nominación suelen iniciarse, de hecho, en los circuitos privados, en las redes afectivas y en nuestro entorno más inmediato, 
para posteriormente ir haciéndose públicos, es decir, ir siendo reconocidos socialmente en contextos sociales más amplios hasta que llega al reconocimiento por parte de las instituciones, que exigen, precisamente, que previamente el nuevo nombre haya sido utilizado durante un período de tiempo en nuestra vida cotidiana ${ }^{16}$.

Los cambios de nombre suponen, en definitiva, la posibilidad de narrarnos de nuevo, de interrumpir ese circuito estable que el nombre propio delimita, creando nuevos itinerarios narrativos a partir de otros nombres que elegimos, que a menudo conviven entre ellos y que son muestra de lo múltiple, fracturado y contradictorio de las identidades. Se produce así un cortocircuito en los sistemas estabilizadores de identidades, cuerpos y sujetos, relatando de nuevo nuestro yo y mostrando que, de hecho, el yo y su nombre propio, no es más que una ficción narrativa que utilizamos para nuestra supervivencia y narratividad social.

\section{Bibliografía}

Austin, J.L. (1998, e.o. 1971): Cómo hacer cosas con palabras, Barcelona, Paidós.

Burgos, E. (2008): Qué cuenta como una vida. La pregunta por la libertad en Judith Butler, Madrid, Antonio Machado Libros.

Butler, J. (1990): El género en disputa. El feminismo y la subversión de la identidad, Barcelona, Paidós, 2007.

Butler, J. (1993): Cuerpos que importan, Buenos Aires, Paidós, 2008.

ButLer, J. (2004, e.o. 1997): Lenguaje, poder e identidad, Madrid, Síntesis.

ButLer, J. (2004): Deshacer el género, Barcelona, Paidós, 2006.

Butler, J. (2010, e.o. 1997): Mecanismos psíquicos del poder, Madrid, Cátedra.

Derrida, J. (1986, e.o.1971): De la gramatología, Madrid, Siglo Veintiuno.

Derrida, J. (1984): Otobiografías: la enseñanza de Nietzsche y la política del nombre propio, Madrid-Buenos Aires, Amorrortu, 2009.

Derrida, J., "Firma, acontecimiento, contexto" en Derrida, J. (1989): Márgenes de la filosofía, Madrid, Cátedra.

Derrida, J. (2011, e.o. 1993): Salvo el nombre, Buenos Aires, Amorrortu.

Foucault, M. (2005, e.o.1976): Historia de la sexualidad. Vol. 1. La voluntad de saber, Madrid, Siglo XXI.

Halberstam, J. (2008): Masculinidad femenina, Madrid, Egales.

${ }^{16}$ Tal es el caso de la legislación española, que para poder cambiar de nombre oficialmente exige haber convivido durante cierto tiempo con el nuevo nombre. 
Kosofsky Sedgwick, E. (1998, e.o. 1990): Epistemología del armario, Barcelona, Ed. de la Tempestad.

KRIPKE, S. (1981): El nombrar y la necesidad, México D.F., UNAM-Instituto de Investigaciones Filosóficas, 1995.

LaCan, J. (2008): Escritos, Buenos Aires, Siglo XXI.

Laclau, E. y C. Mouffe (2006, e.o. 1985): Hegemonía y estrategia socialista. Hacia una radicalización de la democracia, Buenos Aires, Fondo de Cultura Económica.

Latour, B. y E Hermant (1999): "Esas redes que la razón ignora: laboratorios, bibliotecas, colecciones", en García Selgas, F.J. y J.B. Monleón, Retos de la Postmodernidad, Madrid, Trotta.

LoRde, A. (2009, e.o. 1982): Zami. Una biomitografia. Una nueva forma de escribir mi nombre, Madrid, Horas y horas.

McCullers, C., "Frankie y la boda" (2007), en Carson McCullers, El aliento del cielo, Barcelona, Seix Barral.

Platero, L. (2011): "The narratives of transgender rights mobilization in Spain" en Sexualities, 14 (5).

Preciado, B. (2008): Testo Yonqui, Madrid, Espasa Calpe.

Preciado, B. (2011), "La Ocaña que merecemos. Campceptualismo, subalternidad y políticas performativas", en Ocaña, Catálogo exposición, Barcelona, La Virreina.

Romero Bachiller, C. (2008): "Documentos y otras extensiones protésicas, o cómo apuntalar la "identidad"”, Política y Sociedad, 45 (3), pp.139-157.

Spade, D. (2008): “Documenting Gender”, Hastings Law Journal, 59, pp.731.

VALENCIA, S. (2012): Adrift's book (Índigo), Badajoz, Aristas Martínez.

VÁzquez García, F. (1997): "Foucault y la historia social”, Historia Social, 29, pp. 145159.

Villaplana, V.: "Mediabiografía. Tecnologías de la memoria" disponible en $<$ http://www.zemos98.org/IMG/pdf_7_mediabiografia-tecnologias-de-la-memoria_ virginia-villaplana.pdf $>$

Žı̌̌EK, S. (1992, e.o. 1989): El sublime objeto de la ideología, México D.F., Siglo XXI.

VINYES, R. (2002): Irredentas. Las presas politicas y sus hijos en las cárceles franquistas, Madrid, Temas de Hoy.

Zelizer, V. (1985): Pricing the priceless child, Nueva York, Basic Books. 